\title{
Object-Oriented Approach of Landsat Imagery for Flood Mapping
}

\author{
Kanta Tamta \\ MTech CSE Dept. \\ G.B. Pant engineering College,Ghurdauri, \\ Pauri Garwal, Uttrakhand, India
}

\author{
H.S.Bhadauria \\ Assistant professor, CSE Dept. \\ G.B. Pant engineering College,Ghurdauri, \\ Pauri Garwal, Uttrakhand, India
}

\begin{abstract}
This study introduced an object-oriented approach to flood mapping and affected field estimation in central Cambodia. Traditional pixel-based image algorithms for flood mapping and land use and land cover classification endure from low accuracy, sub-pixel problems, and the cover noise effect in the resulting images On the other hand, the object-based image analysis (OBIA) approach has been thoroughly developed in the last two decades to overcome the limitations and disadvantages of the traditional pixel-based approaches by generating and analyzing meaningful image objects instead of individual pixels and reducing the speckle noise effect. The OBIA approach was applied for the image classification with a new improved estimation algorithm with multi scale parameter in the segmentation process to obtain more accurate results in the flood mapping. Flooding can be recognized using a variety of approaches such as statistics, ground-based measuring, prediction model, remote sensing techniques.
\end{abstract}

\section{Keyword}

Change Detection, Classification, Flood Mapping, ObjectBased Approach, Segmentation

\section{INTRODUCTION}

Remote Sensing (RS) and Geographic Information Systems (GIS) techniques provide effective tools for considering the land use and land cover dynamics of the area as well as for observing, mapping and management of natural assets. Some recent studies have shown the use of RS and GIS in land use Change Detection. Geographic Information System (GIS) is a computer based system that offers the abilities for input, data management, data storing and recovery, operation, analysis and output to switch spatial data [7] [8]. GIS provides a wide variety of tools for determining areas affected by flood [5] The main benefit of GIS for flood management and planning is that, it generates visualization of flood prone areas that creates potential to further analysis the product to estimate probable damage due to flood [10] [11]. GIS has been broadly used to gather information from different spatial data, aerial photographs, satellite images and Digital Elevation Model (DEM) [4]. The main focus in this field spins around definition of flood area and preparation of flood mapping and risk maps for the susceptible areas [6]. River flooding in the developing countries of Asia is very important because of their heavy requirement on agriculture but any flood approximation and hazard mapping attempt in this area is handicapped by low availability of high resolution. Flood mapping is a dynamic component for appropriate land use planning in flood prone areas. In the last 30 years, flood has been the most disastrous natural disaster affecting, on an average, about 80 million people per year of the total population affected by any natural disaster, causing economic damage worth over US\$11 million annually around the world.

Flood mapping study helps in organizing the areas causing problems and initially becomes a step towards planning to moderate the harms. Generally inundation is the most devastating, common and frequent natural vulnerability of the world [1]. Apparently, this is, for the large part, due to the heavy rainfall for long days on the upstream highlands [2]. The objective of present study is to describe and discover flood mapping and land cover change assessment at landscape level using Landsat satellite data 2013 in Cambodia. Flood mapping with remote sensing data has been investigated for several years. In the past, the poor availability of appropriate sensors, low temporal resolution, time-consuming data acquisition and limited image analysis techniques Iglseder et al. [1]. Today, major advances reduce these obstructions, improving possibilities for a useful flood mapping tool. In general, two types of mapping products are required by endusers: overview maps of affected areas and damage-maps combined with additional information (e.g. land-use type of flooded area, destroyed traffic routes, changes in flood-levels) Allenbach et al [3] areas. A flood rate map was developed using the multi-date Landsat satellite imagery. Flood affected areas were classified into permanent water and flood water based on vulnerability to the potential of flood hazard. The combination of all thematic layers and flood mapping map was generated to prepare flood hazard and risk map using GIS platform

The vegetation type/land use map was integrated for creation of flood hazard and risk assessment. Flood mapping [4] is necessary not only because flood enforces a curse on the society, but the optimal manipulation of the land, proper management and control of water resources are of dynamic importance for bringing prosperity in the predominantly agriculture based economy of highly populated area. Flood mapping is the vital component in flood moderation measures and land use planning Satellite based remote sensing images have been used to map the extent of flood [7] inundation since the early 1970. Most of the early studies used optical remote sensors, such as Landsat MSS and TM But optical sensors cannot penetrate clouds, which nearly always accompany flood events; so they have been mainly used to observe post flood inundation extent. The present research has the objective prepare vegetation type/ land use map on 150 scale parameter using Landsat satellite data.

Over the last 10 years dramatic river flooding has affected various regions all over the world. Examples of such massive floods are the Meuse (The Netherlands in 1993), the Rhine and the Meuse (The Netherlands, Belgium and Germany in 1995 and 1996), the Oder (Czech Republic, Poland and 
Germany in 1997), the Tisza (Hungary and Rumania in 2000), various rivers in Yorkshire and Midlands (UK in 2000), the Po (Italy in 2000), the Elbe and Styre (Germany and Austria in 2002) and the Gard (France in 2002).Early property damage assessment and accurate modelling of flood events require that private-owned objects, agricultural land use and infrastructure are identified on a land cover map. The new software package eCognition developer 9.1 (eCognition, 2002) brings together several of these contextual and objectoriented approaches and gives promising results for highresolution image analysis. The new method used in this study first extracts image objects by segmentation. The segments are subsequently classified using combinations of spectral and spatial information (Baatz and Schape, 2000). The objective of this study is to investigate the usefulness of high spatial resolution Landsat imagery and segmentation algorithms to produce detailed land cover maps for flood damage assessment.

\section{STUDY AREA AND DATA}

This method was implemented using the Landsat-8, OLI (Operational Land Imager) satellite image courtesy of the U.S. Geological survey covering the part of Cambodia, acquired in May 2013 and October 2013. It is bounded by Thailand to the northwest, Laos to the northeast, and Vietnam to the east, and the Gulf of Thailand to the southwest. The study area lies between $10^{\circ} 30^{\prime} \mathrm{N}$ and $13^{\circ} 45^{\prime} \mathrm{N}$ in latitude, and $103^{\circ} 25^{\prime} \mathrm{E}$ and $106^{\circ} 15^{\prime} \mathrm{E}$ in longitude.

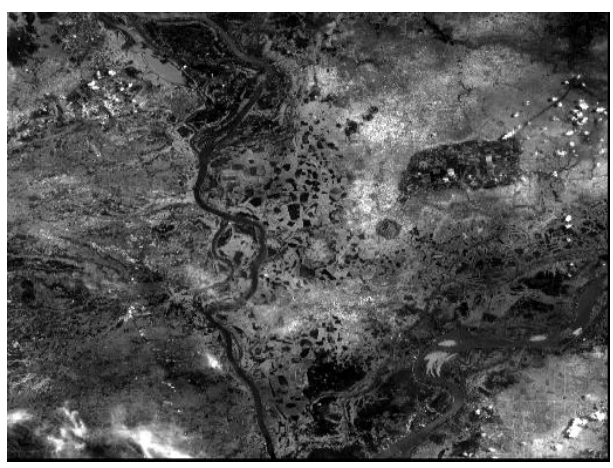

Fig. 1 Before flood Landsat imagery

Generally the OLI requirements specified a sensor that collects image data for nine spectral bands with a spatial resolution of $30 \mathrm{~m}$ over a $185 \mathrm{~km}$ swath from the nominal 705 $\mathrm{km}$ LDCM spacecraft altitude. Landsat 8 contains two sensors: Operational Land Imager (OLI) with 3 new bands (deep blue band for coastal, shortwave infrared band, and a quality assessment band) and Thermal Infrared Sensor (TIRS) with 2 thermal bands (Landsat 8, 2013). The OLI sensor with new coastal band (band1) is new bands that provide more details of the waters and eliminates atmosphere background.

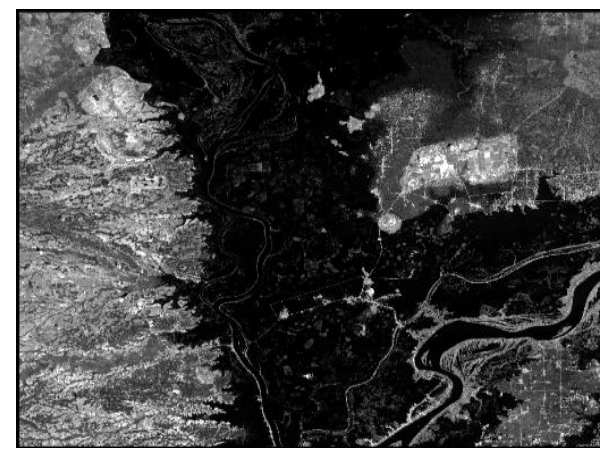

Fig. 2 After flood Landsat imagery

\section{METHODOLOGY}

Object oriented approach to image analysis, include three processes: image segmentation, class hierarchy or image classification and establishing class membership functions [5].Overall design of the study consists main part of flood mapping using Landsat 8 OLI imagery. The flow chart of the study is illustrated in Figure 3.

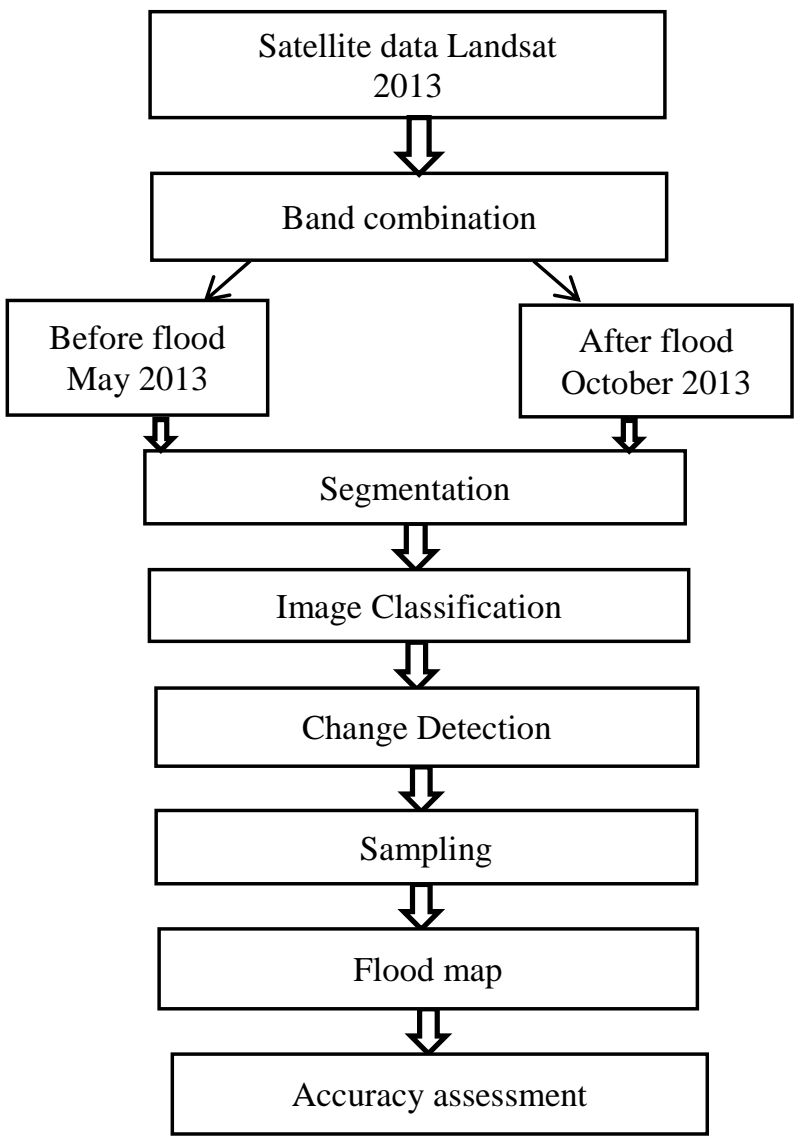

Fig. 3 Flow chart for presented method

\section{A. Image Segmentation}

The main aim of segmentation is to create image objects that correctly denote the shapes and sizes of the water covered areas in the landsat- 8 before flood and after-flood image. The eCognition developer 9.1[11] tools offer various object based classification approach that begins with initial image segmentation process to segment the remote sensing image into homogeneous image object (Definiens, 2001). Multiresolution segmentation is one of the most popular segmentation methods. In multi-resolution segmentation, there are three parameters to be defined: scale parameter, shape parameter and compactness [10]. Thereafter, relations can be defined between image objects since each object knows its context, its neighborhood, and its sub-objects. The default values for shape and compactness are used for initial segmentation, which is 0.1 and 0.5 respectively. Scale parameter [12] is also defined so that the resulting segments are smaller than real objects. Multi-resolution segmentation algorithm, which sequentially merge existing image, objects. eCognition's segmentation algorithm[11] is based on the bottom-up region merging technique. The segmentation method starts at a random point in the image with one-pixel objects, and in a number of segmentation steps, the image objects are bloated to higher pixel clusters (segments) until a certain scale parameter is reached. During the procedure of 
multi resolution segmentation, spatial and shape features are also taken into condition along with the spectral characteristics. The shape parameter is composed of compactness heterogeneity and the smoothness heterogeneity [9].

\section{B. Object-based classification Using Proposed Method}

The proposed methodology of flood mapping was working on the satellite image of Landsat-8 OLI imagery. Based on the segmented image object, the first classification is performed on the before flood image. The aim is to produce an accurate image of the areas covered by water before the flood. The classification is based mainly on the Normalized Difference Vegetation Index (NDVI), NIR band and LWM merged in one object, which is an estimate of the smoothness of a segment.

$$
\begin{aligned}
& N D V I=\frac{(\text { meanNIR-meanRed })}{(\text { meanNIR+meanRd })} \\
& L W M=(M I R) /(\text { GREEN }) * 100
\end{aligned}
$$

The second classification, performed in the after flood image, highlights the areas that are covered by water now but were not in the before flood image. The change detection of flooded areas is based on the water, NDVI, the NIR band, the Brightness of the pixels merged in one object. In addition to the flooded areas, vegetation, agricultural land and cloud are divided to avoid connections with the flood classes. All the classes are defined by the thresholds and not by sample. A classification [13] with the same class definitions applied in the first after flood image shows accurate results for flooded areas. After both flooded area have been classified, now the results of both will be synchronized back to the main map with the help of synchronize map algorithm. At the end of the proposed methodology flooded [7] area will be specified on the main map as both the analysis results from May 2013 and October 2013.This approach allows a simple monitoring of the affected areas, and creation of dynamic flood maps. The same approach could be applied during future environment changes and disaster measures, helping to get faster the invention of rapid mapping products. More research has to be done to check the potential for adjusting the established class definitions to further image from the same or different satellite imagery.

\section{RESULT AND ACCURACY ASSESSMENT}

The segmentation result of the Landsat images with Mutiresolution segmentation scale parameter of 100 and 150 (shape is 0.2, compactness 0.8) is illustrated in Figure 3 and 4.

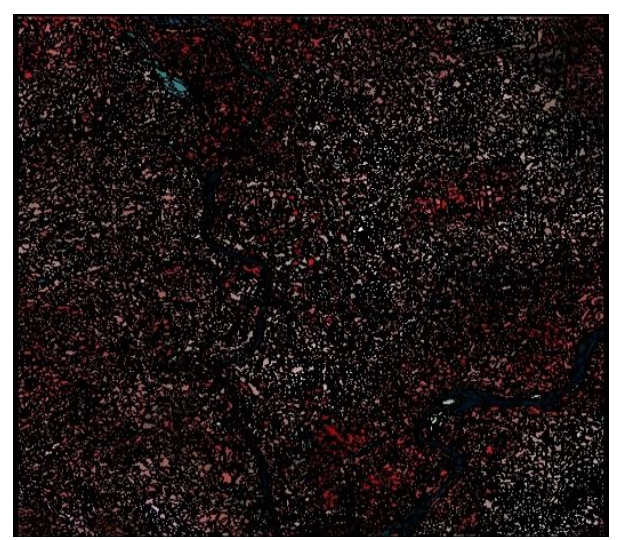

Fig 3.Segmented result with scale parameter 100

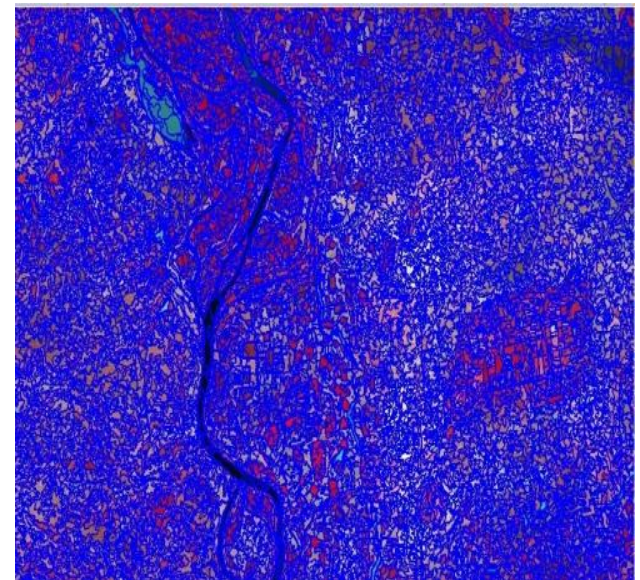

Fig 4 segmented result with scale parameter 150

Both before and after flood images were included in the bottom up region merging segmentation techniques Thus, the water flood image objects were also segmented into smaller objects, which represent the land cover type of the before and after flood area classification for the change detection of the water. Figure 5 and 6 shows the before and after flooded classification. The final classification result of the flood areas in Cambodia in 2013 is shown in Figure 7.

The inundated regions normally occurred along both sides of the Mekong River and Tonal Sap Lake. In this study, not only were the currently flood water areas detected, but also the previously flood regions can be described, based on changes in the vegetation between the before and after flood images, mainly attendant with the changes over the vegetated areas.

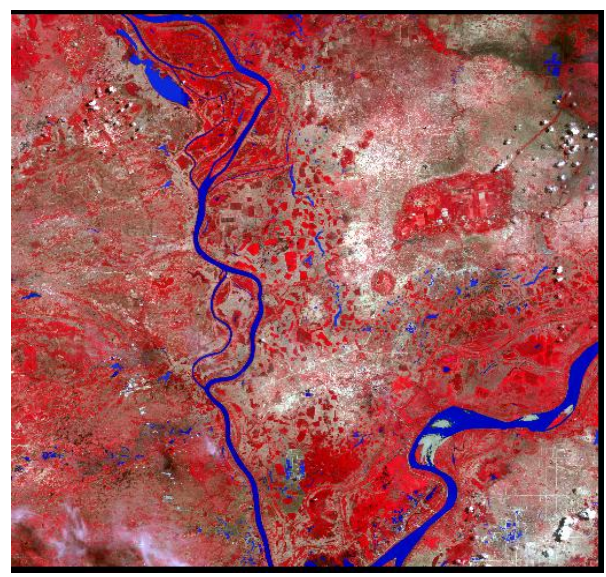

Fig. 5 Water classification before flood

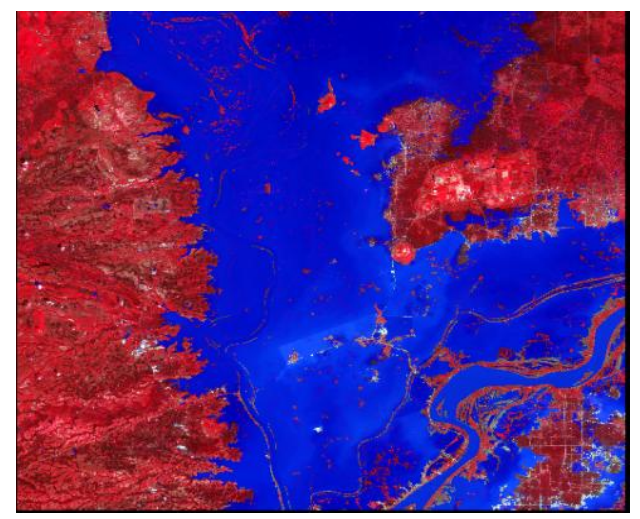

Fig.6 Water classification after flood 


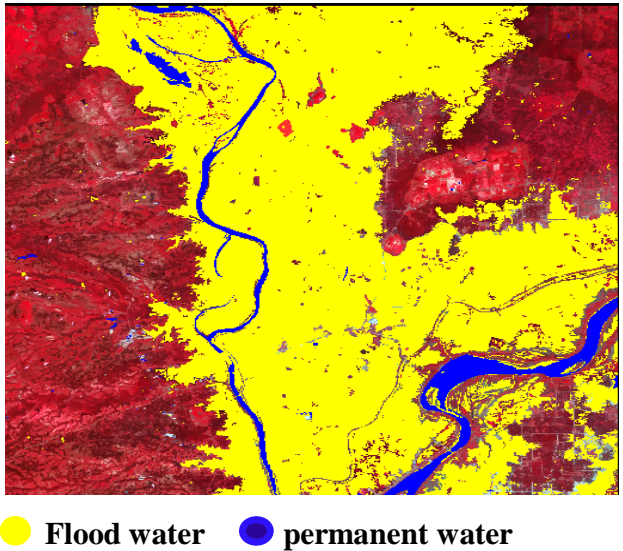

Fig.7 Flood area extraction result from the Landsat 8 images

Therefore, the flood map produced from the Landsat 8 OLI satellite images collected on October 2013 was used to estimate the probability of the approach. It is supposed that the two satellite data with very high spatial resolution provide more precise flood maps, which can be considered as reference data for validating the Landsat-derived flood classification results by constructing the confusion matrix and determining the accuracy assessment. The detailed information of the accuracy assessment for the flood area map is given in Table I. Table II contains the overall accuracy and kappa statistic for image classification. Accuracy assessment is a very important step of the object based image Classification. In this presented method, Error matrix based on TTA mask has been used to calculate the classification accuracy. The overall accuracy and kappa coefficients of the classification results achieved at various scales. Using the manual classification result as sample information, the confusion matrix is generated for the present method. The overall accuracy is 0.97 .

Table 1 Confusion Matrix for the Presented Method

\begin{tabular}{|l|l|l|}
\hline User & $\begin{array}{l}\text { Permanent } \\
\text { water }\end{array}$ & $\begin{array}{l}\text { Flood } \\
\text { water }\end{array}$ \\
\hline $\begin{array}{l}\text { Permanent } \\
\text { water }\end{array}$ & 22431 & 70 \\
\hline Flood water & 89 & 47794 \\
\hline Sum & 22520 & 47864 \\
\hline
\end{tabular}

Table 2 Accuracy Assessment

\begin{tabular}{|c|c|c|}
\hline Use class & $\begin{array}{l}\text { Permanent } \\
\text { Water }\end{array}$ & $\begin{array}{l}\text { Flood } \\
\text { water }\end{array}$ \\
\hline producer & 0.996 & 0.9611 \\
\hline user & 0.9968 & 0.9962 \\
\hline $\begin{array}{l}\text { KIA per } \\
\text { class }\end{array}$ & 0.9841 & 0.8843 \\
\hline
\end{tabular}

\section{CONCLUSIONS}

This study introduced an object-based approach for the flood mapping using the Landsat 8 OLI. The object-based image analysis approach was successfully applied in both flood mapping and land cover change analysis with an employment of multi resolution scale parameter estimation in the image segmentation techniques. The band increment method for the different spectral bands should be further considered to achieve better segmentation and classification results for the flood area. The extracted objects representing the flooded areas can be exported to a GIS and intersected with land-use or population density maps to estimate.

\section{REFERENCES}

[1] Iglseder, H., Arensfischer, W., Wolfensberger, W. 1995, "Small Satellite Constellations for Disaster Detection and Monitoring," Natural Hazards,volume 15, issue 11, pp. 79-85,

[2] Sanyal, J.; Lu, X. 2004, "Application of remote sensing in flood management with special reference to Monsoon Asia: A review," Nat. Hazards, 33, 283-301

[3] Allenbach, B. et al. 2005, "Rapid EO Disaste Mapping Service: Added value,feedback and perspectives after 4 years of Charter actions, SERTIT,

[4] Kundzewicz, Z. W. and Schellnhuber, H. J. 2004, "Floods in the IPCC TAR perspective. Natural Hazards", 31:111-128,.

[5] Uddin, K.; Gurung, D.R.; Giriraj, A.; Shrestha, B. 2013, "Application of remote sensing and gis for flood hazard management: A case study from Sindh Province, Pakistan," Am. J. Geogr. Inf. Syst., 2, 1-5.

[6] Dronova, I.; Gong, P.; Wang, L. 2011, Object-based analysis and change detection of major wetland cover types and their classification uncertainty during the low water period at Poyang Lake,China. Remote Sens. Environ., 115, 3220-3236.

[7] Anil.N.C and Jaishankar.G 2011, "Studies on Land Use/Land Cover and change detection from parts of South West Godavari District, A.PUsing Remote Sensing and GIS Techniques," J. Ind. Geophys. Union, Vol.15, No.4, pp.187-194.

[8] Kuldeep and Kamalesh 2011, "Land Use / Land cover change detection in Doon valley (Dehradun Tehsil), Uttarakhand: using GIS\& Remote Sensing Technique," International Journal of Geomatics \& Geosciences, Vol. 2 Issue 1, pp.34-41.

[9] Symeonakis.E and Koukoulas.S 2009, "A Land use Change and Land Degradation Study in Spain and Greece Using Remote Sensing and GIS,” J. Ind. Geophysics. Union, Vol.14, No.4, pp.180-190.

[10] Pacifici, F., Chini, M., Emery, W.J., "A neural network approach using multi-scale textural metrics from very high-resolution panchromatic imagery for urban land-use classification", Remote Sensing. Environment,.

[11] eCognition User Guider 4, Defines Imaging, 2003

[12] Kiema, J.B.K. 2002, "Texture analysis and data fusion in the extraction of topographic objects from satellite imagery", International Journal of Remote Sensing,

[13] Xie 2005, "Object Oriented Classification, Remote Sensing Image Process and Analysis,". 